\title{
Geokimia Daerah Panasbumi Gunung Pandan, Kabupaten Bojonegoro, Jawa Timur
}

\author{
Hanindya Ramadhani ${ }^{1 *}$, Herning Dyah K. Wijayanti ${ }^{1}$, Paramitha Tedja Trisnaning ${ }^{1}$ \\ ${ }^{1}$ Sekolah Tinggi Teknologi Nasional, Sleman, Yogyakarta.
}

\begin{abstract}
Abstrak
Pulau Jawa memiliki potensi sumberdaya panasbumi yang tinggi, dibuktikan dengan se-kitar $70 \%$ jumlah lapangan panasbumi yang telah beroperasi di Indonesia terletak di Pulau Jawa. Sebagian besar prospek yang telah diidentifikasi berasosiasi dengan gunungapi, khususnya yang berumur Kuarter. Eksplorasi dan eksploitasi panasbumi di Pulau Jawa, hingga saat ini banyak berfokus di Jawa Tengah dan di bagian timur Jawa Barat. Minimnya penyelidikan panasbumi di daerah Jawa Timur menyebabkan kurangnya informasi mengenai sistem panasbumi di wilayah ini.

Gunung Pandan merupakan salah satu gunungapi yang terletak di wilayah Kabupaten Bojonegoro, Provinsi Jawa Timur. Kehadiran manifestasi mataair panas dan kolam lumpur menjadi salah satu indikasi prospek energi panasbumi. Penelitian terhadap kehadiran manifestasi panasbumi dapat menjadi referensi dalam melakukan penyelidikan detail potensi panasbumi di daerah ini. Pengamatan geologi lapangan dan pengambilan sampel air pada lokasi mataair panas dan kolam lumpur mencakup koordinat dan ketinggian lokasi pengambilan sampel, jenis litologi, serta temperatur dan $\mathrm{pH}$ manifestasi. Sampel air diuji di laboratorium guna mengetahui kandungan unsur kimianya, selanjutnya dilakukan analisis terkait tipe fluida dan geotermometer.

Daerah Gunung Pandan, terutama pada setiap lokasi penyelidikan, tertutup endapan limonit dan sebagian lokasi dijumpai adanya travertine. Hasil analisis menunjukkan fluida di ke empat daerah memiliki tipe Sodium Klorida yang dicirikan dengan kandungan $\mathrm{Na}+\mathrm{K}$ dan $\mathrm{Cl}$ yang tinggi, serta memiliki sifat air dewasa. Hasil analisis geothermometer, diperkirakan temperatur terendah reservoir sebesar $153^{\circ} \mathrm{C}$ dan temperatur tertinggi reservoir sebesar $222^{\circ} \mathrm{C}$.
\end{abstract}

Kata Kunci : Kolam lumpur; Gunung Pandan; manifestasi; mataair panas; panasbumi.

\begin{abstract}
Java has a high potential of geothermal resources, as evidenced by $70 \%$ of geothermal fields that have been operating in Indonesia located on Java. Most of the prospects that have been identified were associated with volcanoes, especially Quaternary volcanoes. Geothermal exploration and exploitation in Java, has focused on Central Java and in the eastern part of West Java. Due to, the lack of geothermal investigations on East Java, caused little information of the geothermal system in this region.

Gunung Pandan is one of the volcanoes located in the Bojonegoro Regency, East Java Province. The presence of manifestations of hot springs and mud pools is one indication of the prospect of geothermal energy. Research of geothermal manifestations can be a reference in conducting detailed investigations of geothermal potential in this area. Field geological observations include the coordinates and elevation of the sampling location, type of lithology, temperature and $\mathrm{pH}$ of the manifestation. Water samples were tested in the laboratory to obtain the chemical constituents, then an analysis was carried out to determine the fluid type and geothermometer.

Each stopsite within research area is covered by limonite, and in several area, Jari and Selogaja, were also covered by travertine. Geochemistry analysis shown each hot springs or mud samples had fluid type of Sodium Chloride, which was characterized by a high content of $\mathrm{Na}+\mathrm{K}$ and $\mathrm{Cl}$, and had the characteristics of mature water. The results of the geothermometer analysis estimated that reservoir lowest temperature was $153^{\circ} \mathrm{C}$ and the highest temperature was $222^{\circ} \mathrm{C}$.
\end{abstract}

Keywords: Mud pool; Gunung Pandan; manifestation; hot spring; geothermal.

*) Korespondensi: r.hanindya89@gmail.com 


\section{PENDAHULUAN}

Pulau Jawa merupakan wilayah dengan banyak gunungapi, baik dalam kondisi mati, dorman maupun masih aktif. Kehadiran gunungapi di Pulau Jawa menjadikanya sebagai pusat pengembangan panasbumi di Indonesia. Kementerian Energi dan Sumber Daya Mineral (ESDM) telah melakukan estimasi besar total sumber daya panasbumi di Indoesia sebesar 27.000 MW. Namun, baru sekitar $800 \mathrm{MW}$ yang telah dikembangkan pada tujuh lokasi dengan lima diantaranya berada di Pulau Jawa (Setijadji, 2010).

Gunung Pandan merupakan salah satu gunungapi yang terletak di Kabupaten Bojonegoro, Propinsi Jawa Timur dengan manifestasi panasbumi berupa mataair panas dan kolam lumpur. Penyelidikan geologi diperlukan untuk mengetahui seberapa besar potensi panasbumi serta bagaimana sistem panasbumi ada. Munculnya manifestasi mata air panas dan semburan lumpur dapat dipakai sebagai data untuk mengukur besarnya potensi dan bagaimana sistem panasbumi yang ada di wilayah ini.

\section{Geologi Regional}

Daerah penyelidikan berada di bagian Selatan dari Peta Geologi lembar Bojonegoro dengan skala 1:100.000 (Pringgoprawiro dan Sukido, 1992). Gunung Pandan merupakan gunung api berumur Pliosen yang tersusun oleh batuan terobosan (intrusi) andesit dan breksi gunung api. Berdasarkan pembagian fisiografi regional dari Van Bemmelen (1949), gunung ini terletak di Zona Kendeng.

Zona Kendeng meliputi deretan pegunungan dengan arah memanjang timur - barat (T-B) yang terletak langsung di sebelah utara Subzona Ngawi. Pegunungan ini tersusun oleh batuan sedimen laut yang telah mengalami deformasi secara intensif membentuk suatu antiklinorium (rangkaian perbukitan antiklin kecil yang tersusun secara paralel dan membentuk struktur antiklin lebih besar). Pegunungan ini mempunyai panjang $250 \mathrm{~km}$ dan lebar maksimum $40 \mathrm{~km}$ (de Genevraye \& Samuel, 1972) membentang dari Gunungapi Ungaran di bagian barat ke timur melalui Ngawi hingga daerah Mojokerto (Gambar 1). Di bawah permukaan, kelanjutan zona ini masih dapat diikuti hingga di Selat Madura.

Di bagian tengah Zona Kendeng, yaitu di baratlaut Nganjuk, sabuk Antiklinorium Kendeng diterobos oleh tubuh Gunungapi Pandan yang berumur Pleistosen Awal (Lunt dkk., 1998). Meski demikian, pola struktur perlipatan Kendeng di sekitar Gunung Pandan yang mengalami pembelokan relatif simetris terhadap tubuh gunungapi tersebut mengindikasikan bila volkanismenya terjadi bersamaan dengan proses pengangkatan tektonis Kendeng (Pliosen Akhir).

Ditinjau dari jarak relatif terhadap deretan busur gunungapi dan palung subduksi, Gunungapi Pandan berada satu deretan dengan Gunungapi Ungaran, yaitu menempati posisi volkanisme belakang busur dekat (near backarc). Gunungapi Ungaran juga mulai aktif pada waktu bersamaan dengan Gunungapi Pandan, yaitu Pleistosen Awal (van Bemmelen, 1949). Sebagian besar litologi penyusun Zona Kendeng adalah batulempung-napal-batupasir yang mempunyai kompaksitas rendah, misalnya pada Formasi Pelang, Formasi Kerek dan Formasi Kalibeng (de Genevraye dan Samuel, 1972; Pringgoprawiro, 1983).

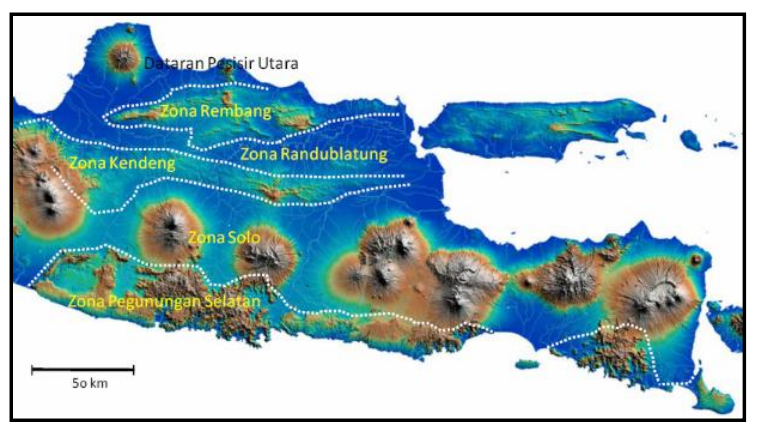

Gambar 1. Pembagian Fisiografi Jawa Timur berdasarkan Van Bemmelen (1949).

\section{METODOLOGI}

Metode yang digunakan dalam penelitian ini berupa pengambilan sampel air berdasarkan prosedur menurut Nicholson (1993) yang kemudian dilakukan analisis kimia air. Tahapan penelitian dijelaskan pada Gambar 2. Pengambilan data lapangan dilakukan guna memperoleh kondisi geologi dan sifat kimia dari setiap manifestasi. Data yang dicatat mencakup koordinat, kondisi geologi pada setiap lokasi dan sifat kimia (pH, TDS, dan DHL) mataair panas maupun lumpur. Selanjutnya, dilakukan pengambilan sampel air panas dan lumpur yang disimpan dalam wadah gelap tertutup. Sampel air panas dan lumpur diuji di laboratorium untuk mengetahui kandungan unsur kimianya. 


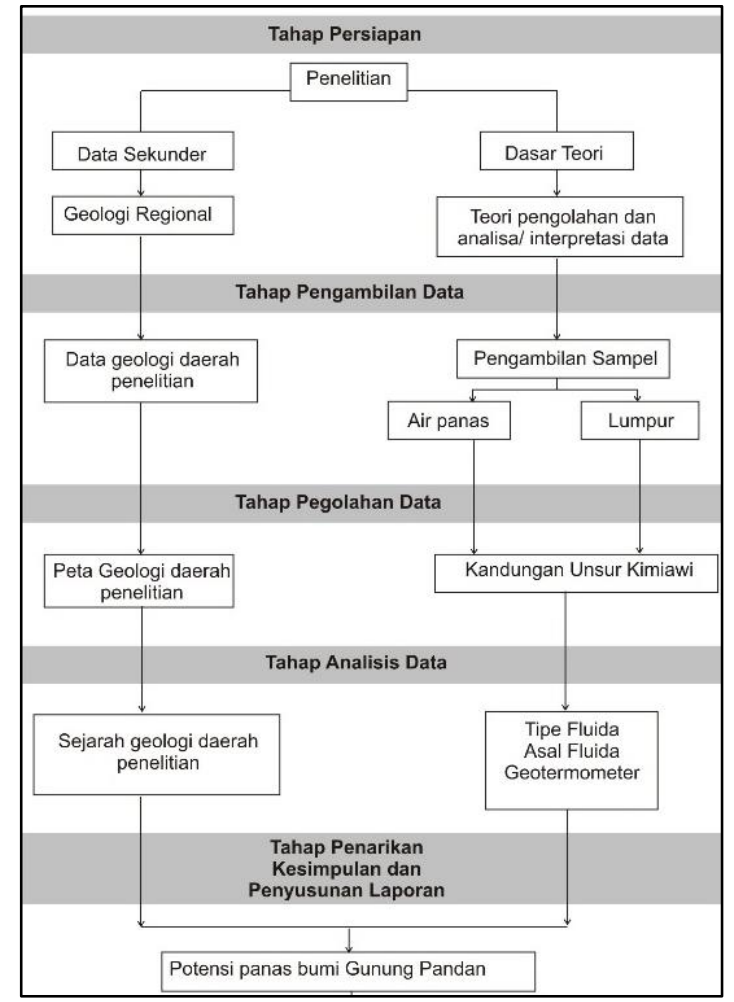

Gambar 2. Diagaram alir penelitian.

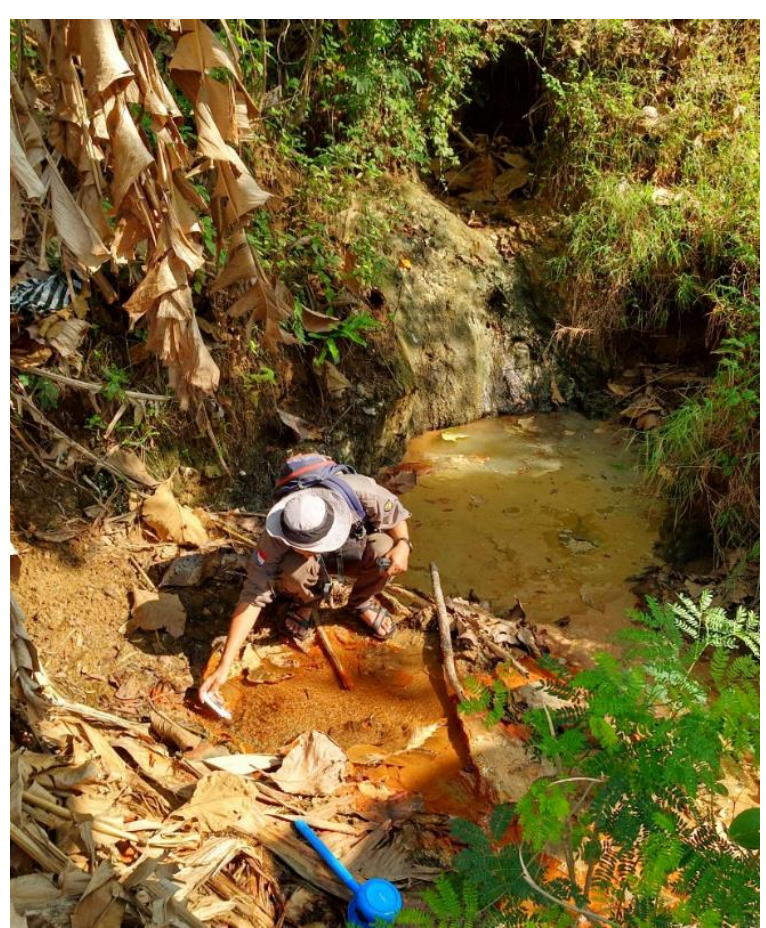

Gambar 3. Pengambilan data $\mathrm{pH}$, TDS, dan DHL, serta sampel air di daerah Jari. Dijumpai travertine dan endapan besi pada lokasi ini.

Tabel 1. Lokasi pengambilan sampel dan sifat kimia setiap manifestasi.

\begin{tabular}{lcccc}
\hline Sifat kimia & Banyukuning & Jari & Selogajah & Kramat \\
\hline Koordinat & 589140 & 590358 & 589983 & 588421 \\
Elevasi & 9176773 & 9180576 & 9180576 & 9180416 \\
Suhu Sampel $\left(\mathrm{C}^{\circ}\right)$ & 496 & 216 & 207 & 310 \\
Suhu Udara $\left(\mathrm{C}^{\circ}\right)$ & 35 & 43 & 55 & 46 \\
Kelembaban $(\%)$ & 29 & 31,8 & 30,5 & 35,4 \\
Warna & 65 & 55 & 71 & 49 \\
Bau & Bening & Bening & Bening & Abu-abu gelap \\
DHL & Karat & Belerang & Belerang & Belerang \\
TDS (ppm) & 2.524 & 6.036 & 7.264 & 9.404 \\
Debit $(\mathrm{L} / \mathrm{s})$ & 1.276 & 2.500 & 3.863 & 5.765 \\
pH & 0,03 & 2,38 & 1,72 & 2,30 \\
Keterangan & 6 & 7 & 8,5 & 8 \\
& Endapan & Travertine \& & Endapan limonit & Bau sangat \\
\end{tabular}

Analisis data hasil uji laboratorium dilakukan menggunakan Diagram Segitiga $\mathrm{Cl}-\mathrm{SO}_{4}-\mathrm{HCO}_{3}$, Diagram Segitiga Na-K-Mg untuk menentukan tipe fluida dan geotermometer. Lokasi pengambilan data lapangan dapat dilihat pada Gambar 4.

\section{HASIL}

Pengambilan Data Lapangan

Hasil pengambilan data lapangan dari setiap manifestasi dapat dilihat pada Tabel 1 . Suhu terendah $32^{\circ} \mathrm{C}$ dijumpai pada lokasi pengamatan Banyukuning (Gambar 5), sedangkan suhu tertinggi adalah $58^{\circ} \mathrm{C}$ pada lokasi pengamatan 
Jari (Gambar 3). Debit air < 2 L/detik dan $\mathrm{pH}$ rata-rata di antara 6 - 8. Pada daerah Banyukuning dijumpai kandungan $\mathrm{Fe}$ cukup banyak, dibuktikan dengan adanya warna karat yang menutupi batuan pada daerah tersebut (Gambar
5). Pada daerah Jari dan Selogajah (Gambar 6), tidak dijumpai endapan Fe, tetapi berkembang endapan travertine yang mendominasi daerah tersebut. Daerah Kramat (Gambar 9) menunjukkan warna air abu-abu gelap.

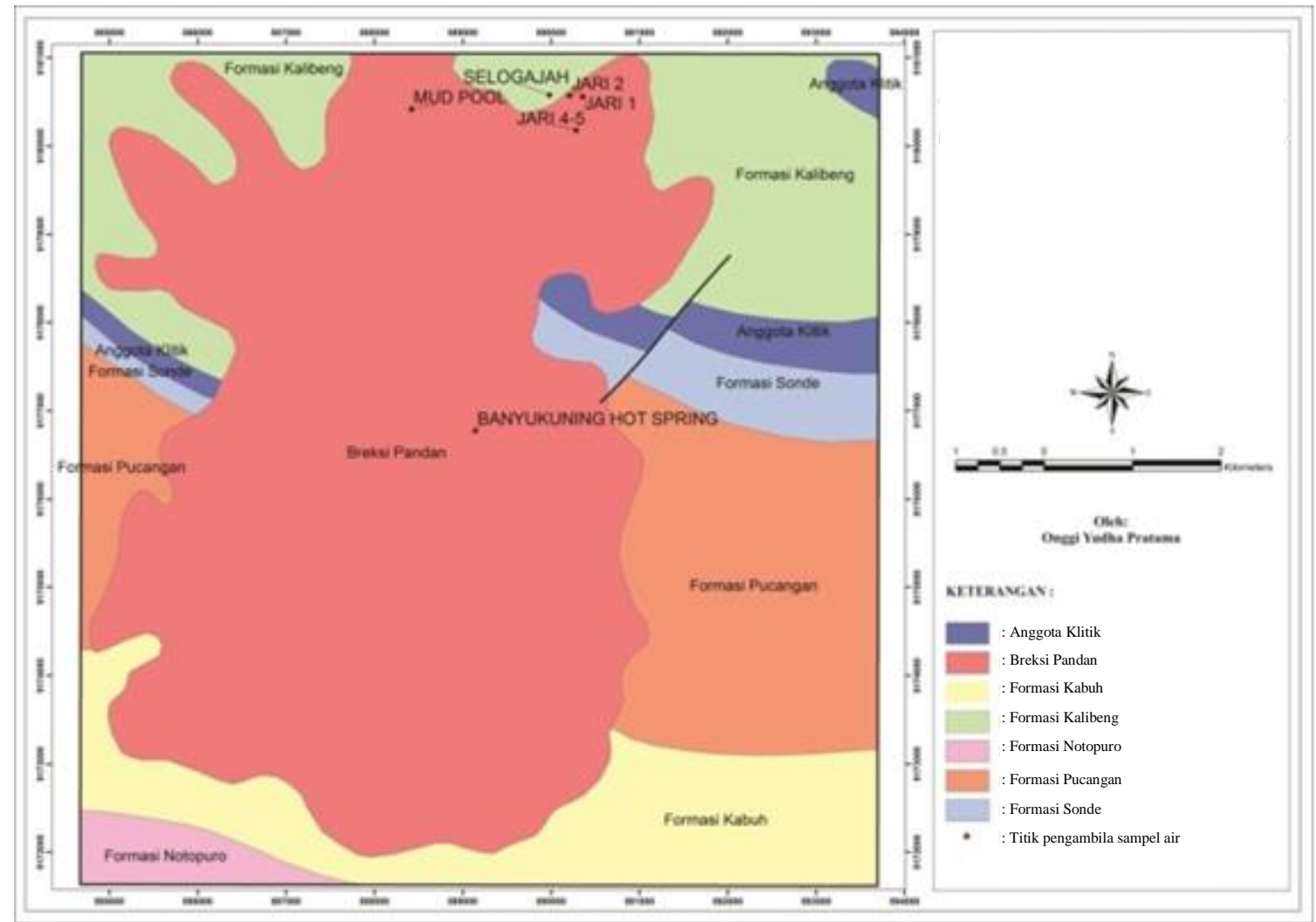

Gambar 4. Peta geologi dan lokasi pengambilan sampel air daerah Gunung Pandan dan sekitarnya.

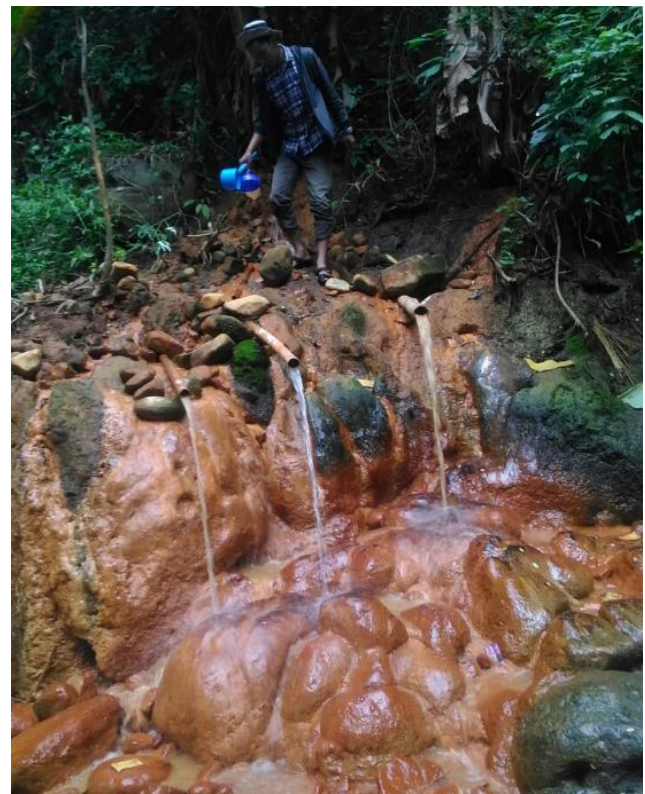

Gambar 5. Batuan dengan warna karat akibat tingginya kandungan $\mathrm{Fe}$ pada lokasi pengambilan sampel di daerah Banyukuning.

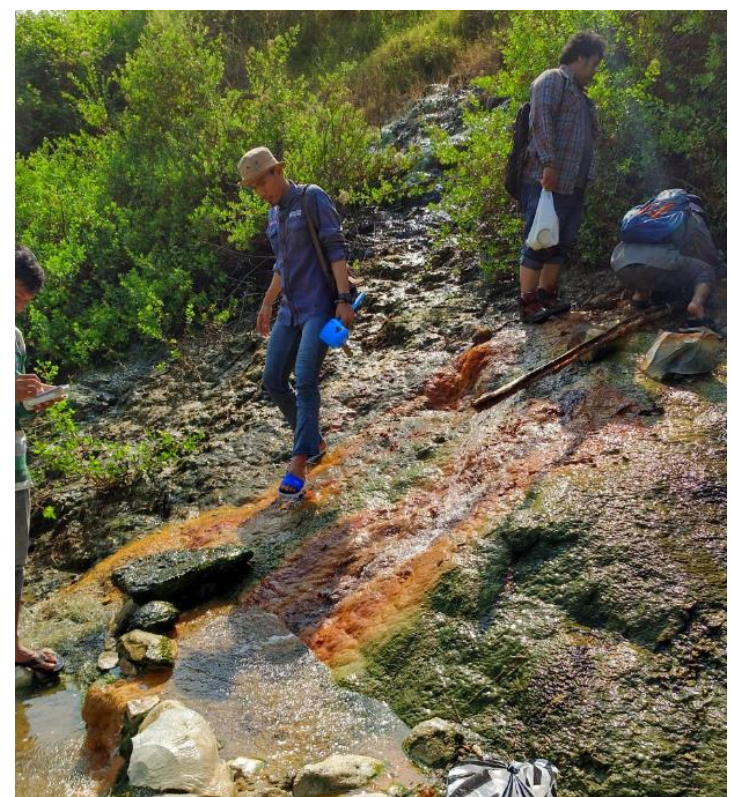

Gambar 6. Lokasi pengambilan sampel airpanas di daerah Selogajah. 


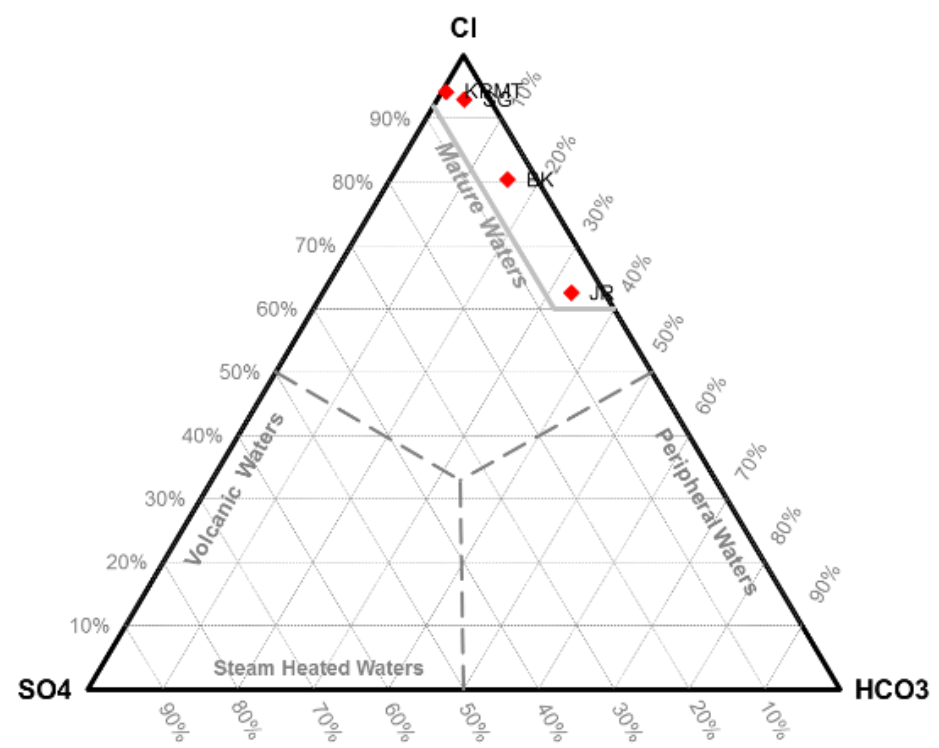

Gambar 7. Hasil plot jenis fluida pada diagram $\mathrm{Cl}-\mathrm{SO}_{4}-\mathrm{HCO}_{3}$

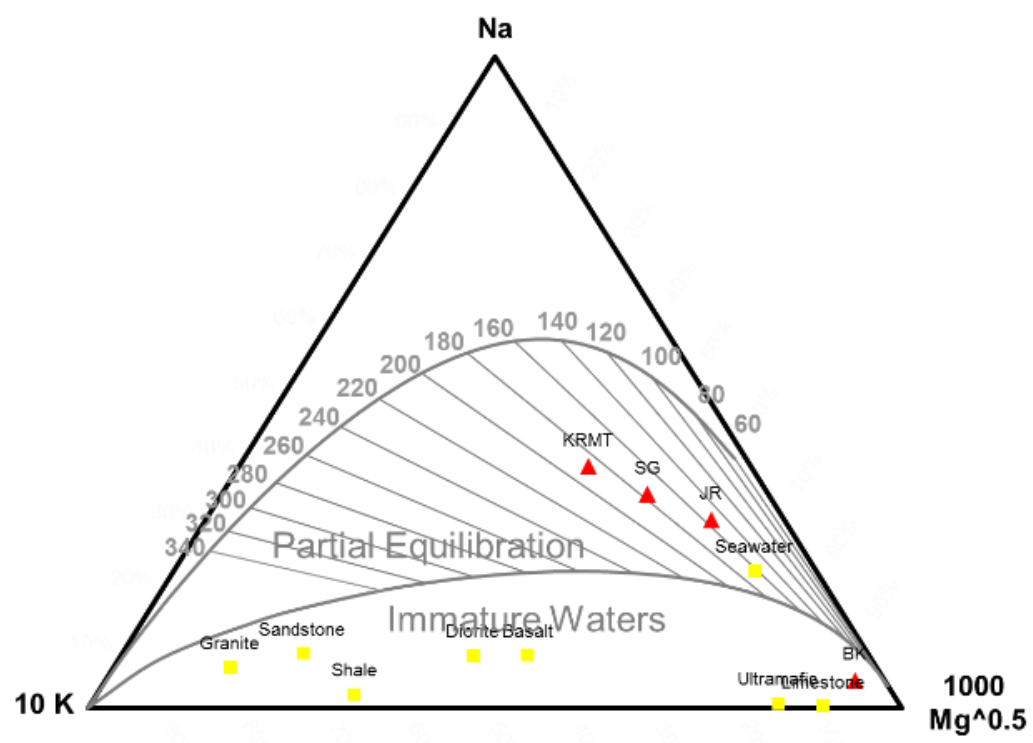

Gambar 8. Diagram Segitiga K-Na-Mg

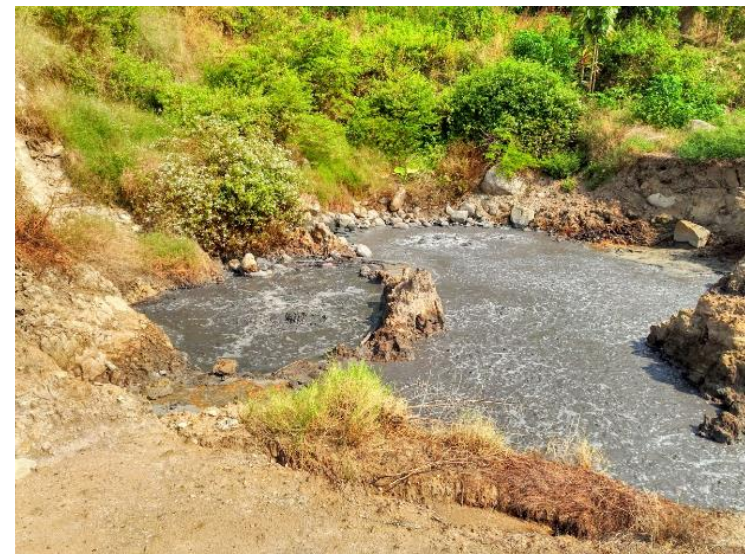

Gambar 9. Lokasi pengambilan sampel lumpur di daerah Kramat.
Tabel 2. Hasil penghitungan Geotermometer

\begin{tabular}{lc}
\hline \multicolumn{1}{c}{ Sampel } & $\mathrm{Na} / \mathrm{K}$ \\
& (Giggenbach, 1988) \\
\hline Jari & 153 \\
Banyukuning & 222 \\
Sokogajah & 176 \\
Keramat (lumpur) & 187 \\
\hline
\end{tabular}

\section{Analisis Geokimia Air Panas}

Tipe Fluida

Pengguanaan komponen anion yang berupa $\mathrm{Cl}$, $\mathrm{SO}_{4}, \quad \mathrm{HCO}_{3}$ bermanfaat untuk mengetahui komposisi fluida panas bumi karena anion-anion tersebut merupakan zat terlarut yang paling 
banyak dijumpai dalam fluida panasbumi. $\mathrm{Cl}$, $\mathrm{SO}_{4}$, dan $\mathrm{HCO}_{3}$ dapat digunakan untuk menginterpretasi kondisi dan proses yang berlangsung di dekat permukaan (kurang dari 1 km) (Herdianita, 2006).

Konsentrasi $\mathrm{Cl}$ tinggi dalam mata air mengindikasikan air berasal langsung dari reservoir, dengan minimal pencampuran atau pendinginan secara konduksi. Kadar $\mathrm{Cl}$ rendah pada air (yang tidak menunjukan karakteristik uap panas) dari mata air panas adalah karakteristik dari pengenceran air tanah. Konsentrasi dapat berkisar dari $<10$ sampai $>100.000 \mathrm{mg} / \mathrm{kg}$. Nilai hasil analisis laboratorium pada sampel fluida panas bumi kemudian dipasang pada diagram segitiga $\mathrm{Cl}-\mathrm{SO}_{4}-\mathrm{HCO}_{3}$ (Gambar 7) dan menunjukkan bahwa jenis fluida sistem panasbumi di daerah penelitian adalah mature water.

\section{Geotermometer}

Geotermometer yang diterapkan pada penghitungan ini adalah metode Na-K-Ca (Gambar 8). Pemilihan geotermometer ini didasarkan pada kandungan $\mathrm{Ca}$ yang tinggi dengan landasan teori yang bersifat empiris dan belum dipahami secara maksimal (Giggenbach, 1988). Batasan teoritis untuk geotermometer ini adalah ekuilibrium antara $\mathrm{Na}$ dan K-Feldspar serta konversi mineral kalsium alumino silikat (misalnya plagioklas) menjadi kalsit. Hasil penghitungan geotermometer diperoleh temperatur reservoir setiap manifestasi yang ditunjukkan pada Tabel 2.

Sebagai catatan bahwa penghitungan geotermometer ini telah disesuaikan dengan ion balance dari anion dan kationnya. Sehingga data yang dapat dipakai adalah data geokimia Jari dengan perkiraan panas reservoir $153^{\circ} \mathrm{C}$ (ion balance $<5 \%$ ).

\section{KESIMPULAN}

Daerah Gunung Pandan, terutama pada setiap lokasi penyelidikan tertutup endapan Limonit dan di sebagian lokasi dijumpai travertine. Daerah Banyukuning, Jari, Selogajah, dan daerah Kramat memiliki tipe Sodium Klorida yang dicirikan dengan kandungan $\mathrm{Na}+\mathrm{K}$ dan $\mathrm{Cl}$ yang tinggi, serta memiliki sifat air dewasa. Temperatur terendah reservoir dari sistem panasbumi ini adalah sebesar $153^{\circ} \mathrm{C}$ dan temperatur tertinggi reservoir sebesar $222^{\circ} \mathrm{C}$.

\section{UCAPAN TERIMA KASIH}

Pertama-tama kami sampaikan terimakasih kepada Kementrian Riset dan Teknologi dan Pendidikan Tinggi yang telah mendanai penelitian ini. Terima kasih juga disampaikan kepada Munif Nur Faizin, Onggi Yudha Pratama, Adhitama, Yahdy, Damas Muharif.

\section{DAFTAR PUSTAKA}

de Genevraye, P. dan Samuel, L., 1972. Geology of The Kendeng Zone (Central \& East Java). Proceedings of the Indonesian Petroleum Association 1st Annual Convention and Exhibition, hal. 17-30.

Giggenbach and Goguel. 1989. Chemical Techniques in Geothermal Exploration. Chemistry Division, DSIR, Private Bag.: New Zealand.

Herdianita, N. R. dan Priadi, B., 2006, Manifestasi Permukaan Sistem Panasbumi Gunung Kendang - Angsana, Garut Pameungpeuk, Jawa Barat. Jurnal Geoaplika Volume 1, Nomor 1, hal. 047-054.

Lunt, P., Netherwood, R., dan Huffman, O.F., 1998. Guide Book of IPA Field Trip to Central Java. Proceeding of $24^{\text {th }}$ Annual Convention Indonesian Petroleum Association, Jakarta, hal. 65.

Nicholson, K., 1993. Geothemal Fluids Chemistry and Exploration Technique. School of applied sciences. The Robert Gordon University Aberdeen AB1 1HG, Scotland: United Kingdom.

Pringgoprawiro, H., 1983. Biostratigrafi dan Paleogeografi Cekungan Jawa Timur Utara, Suatu Pendekatan Baru. Desertasi Doktor, Institut Teknologi Bandung.

Pringgoprawiro, H. dan Sukido., 1992. Peta Geologi Lembar Bojonegoro, Jawa. Pusat Penelitian dan Pengembangan Geologi: Bandung.

van Bemmelen, R. W., 1949. The Geology of Indonesia, vol.1.A: General Geology. Martinus Nijhof, The Haque, hal. 684. 